\title{
PATTERNS OF SEXUAL DIMORPHISM AND PHENETIC VARIETYAMONG THE POPULATIONS OF THE GOLDEN JACKAL (Canis aureus) IN BULGARIA: INSIGHTS FROM CRANIOMETRIC DATA
}

\author{
Markov G. G. ${ }^{1}$, Kocheva1 M. A. ${ }^{1}$, Gospodinova M. G. ${ }^{1}$
}

Summary: A population craniometric analysis of the golden jackal (Canis aureus) from Bulgaria was carried out using 18 linear skull and dental parameters. The analysis included 106 individuals (52 males and 54 females), originating from 3 geographic populations with different density. Age variation, sexual dimorphism and geographic variation of the size of the cranium were assessed order to resolve the phenetic similarity of the Bulgarian golden jackal populations. The obtained data confirmed the high degree of sexual dimorphism of the skull. The multivariate statistical assessment of the population skull features in the adult Bulgarian golden jackals, performed separately by gender, demonstrated that at population level in both sexes they have resolution ability and can be used for classification of the individuals to certain geographic populations of the species in Bulgaria. Moreover, the patterns of population craniological variation manifested low degree of craniological similarity among the golden jackals inhabiting the Eastern (Southern and South-western Bulgaria) and Western (Dalmatia, Croatia) Balkans, whereupon revealing their craniometric heterogeneity in the Balkan Peninsula. Thus, it is necessary to use the morphometric data in combination with other methods to establish the phenetic similarity between golden jackal populations, especially at subspecies rank in the Balkan Peninsula.

Keywords: Golden jackal, Canis aureus, Bulgaria,craniometric identity, craniological variation, phenetic similarity

\section{Introduction}

A population craniometric analysis of the golden jackal (Canis aureus) from Bulgaria was carried out using 18 linear skull and dental parameters. The analysis included 106 individuals (12 juveniles;40subadultsand 54adults), originating from 3 geographic populations with a different density. In order to reveal the phenetic similarity of the Bulgarian golden jackal, age variation, sexual dimorphism and geographic variation of the cranium size were assessed. The obtained data confirmed the high degree of sexual dimorphism of the skull. The multivariate statistical assessment of the population skull features in the adult Bulgarian golden jackals, performed separately by gender, demonstrated that they have resolution ability at population level in both sexes and can be used for classification of the individuals to certain geographic populations of the species in Bulgaria. Moreover, the patterns of population craniological variation manifested a low degree of craniological similarity among the golden jackals inhabiting the Eastern (Southern and South-western Bulgaria) and Western (Dalmatia, Croatia) Balkans, whereupon revealing their craniometric heterogeneity on the Balkan Peninsula. Thus, it is necessary to use the morphometric

\footnotetext{
${ }^{1}$ Georgi G. Markov, Maria A. Kocheva, Milena G. Gospodinova, Institute of Biodiversity and Ecosystem Research, Bulgarian Academy of Sciences, Tzar Osvoboditel Blvd. № 1, 1000 Sofia, Bulgaria
} 
data in combination with other methods to establish the phenetic similarity between golden jackal populations, especially at subspecies rank on the Balkan Peninsula.

\section{Introduction}

As a result of a study on the divergence of mitochondrial and nuclear genomes of the golden jackals from Eurasia and Africa Koepfli et al. (2015) have found out that they are genetically distinct lineages. Thedifferences between these lineages were sufficient to describe them as completely different biological species: Canis aureus (Eurasian golden jackal) and C. athus (African golden wolf). The high ecological plasticity of the golden jackal (Canis aureus) allows it to settle a large geographic range covering the territories of South-eastern Europe and South Asia (Jhala and Moehlman, 2008). In Europe, over the past years, the species range expanded from the Balkans northwards and westwards. In particular, the presence of the golden jackal was recorded in Hungary, Slovakia, Austria, Italy, Ukraine, Belarus, Poland, Estonia and Lithuania (Arnold et al., 2011; Trouwborst et al., 2015).

Until the early 1960s, the golden jackal in Bulgaria occurred only in the region of Strandja Mountain, in the Southeast part of the country (Botev et al., 1979; Spassov, 1989). Since then its abundance began to increase rapidly, and soon the golden jackal occupied lowland and hilly habitats in the country and extended its distribution westwards and north-westwards from the original habitats in Strandja-Sakar area (Spassov, 2007; Markov, 2012). It seems that the largest jackal population in Europe occurs in Bulgaria (Markov, 2011a).

Generally, the main habitats of the golden jackal in Bulgaria could be classified as forested localities in the lowland fields in agricultural regions and woodland habitats in hilly areas in the country. The ecological conditions and the food base in these main biotopes are quite different and they determine the distribution, local abundance and population density of golden jackals in Bulgaria (Pomakov, 1981; Spassov, 2007; Markov, 2012;Stoyanov, 2012). Therefore, the investigation of craniological diversity of the golden jackal in Bulgaria should cover populations inhabiting the both main types of biotopes - forested semi-mountainous and forested highland fields.

Several attempts have been made to determine the craniometric features of the golden jackals inhabiting the territory of Bulgaria. In general terms, the compiled data represented linear characteristics of the skulls, derived either from few specimens (Atanasov, 1953; Kryštufek and Tvrtkovic, 1990), or from an aggregated group of jackals, formed by animals from the entire country (Stoyanov, 2012).

Considering the lack of detailed knowledge on the craniological identity of the golden jackal in Bulgaria, our general aim was to assess the age, sexual and geographic diversity of its cranium and to reveal its population phenetic variety in the country.

\section{Material and Methods}

The specimens, included into the comparative craniometric analysis, were taken from two populations from hilly woodlands (POP_1 andPOP_3) and one population (POP_2) from lowland fields (Fig. 1). 


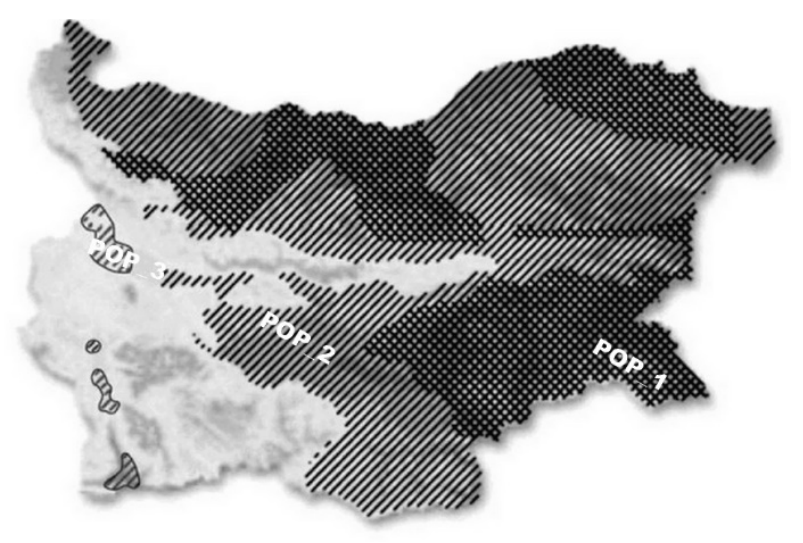

Figure 1. Location of the studied golden jackal populations on the background of the contemporary distribution and the relative density of the golden jackal (Canis aureus) in Bulgaria

Legend: POP_1 - Sakar-Strandzha region, POP_2 - the Upper Thracian Plain and POP_3 - the western part of the Sub-Balkan valleys. Shaded areas denote a moderate to a low density; crossed areas indicate a high density, patches to the west show isolated population clusters, according to the graphic information by Spassov, 2007 and the numerical information by AEFA, 2014

These populations were as follows: Population 1 (POP_1), inhabiting Sakar-Strandja subregion of Thracian-Strandja region; Population 2 (POP_2) from the lowland fields in agricultural region in Upper Thracian Plain and Population 3 (POP_3) inhabiting the western part of The SubBalkan valleys (Georgiev, 1991). The relative population density of the jackal was different in those three regions. POP_1 had high density, POP_2 had medium density and POP_3 had low density (Spassov, 2007; Markov, 2011b).

The age craniometrical variability was described in three age groups: “juvenile” - up to 1 year, "subadult" - between 1 and 2 years and "adult" - over 2 years. These groups were determined considering the biological and morphological features of the age development of the golden jackal: (i) although the male and female golden jackals reach sexual maturity between the first and the second year, the young golden jackals remain with the adults for up to two years and only after that they start living independently as adults (Novice, 1956; Nowak, 1991; Sillero-Zubiri et al., 2004); (ii) the basal cranial synchondroses become fully ossified after the age of two years (Raychev et al., 1999). The age of the specimens was determined according to the upper incisive teeth wear (Lombaard, 1971; Raychev et al., 1999).

The comparative craniometric study included 106 specimens from Bulgaria. The specimens were classified into three age groups as follows: 12juveniles (6 males and 6 females); 40subadults,(17 males and 23 females) and 54adults(29 males and 25 females). The analysed sample from Bulgaria consisted of specimens, kept in the scientific collections of public institutes such as Natural History Museum (Sofia), Institute of Zoology (BAS), collections of different hunting enterprises in the country, but the biggest part of them (about $55 \%$ ) belonged to private collections.

Only adult specimens were included into the analyses aiming to determine the population cranial sexual dimorphism and the inter-population relationships in the skull characters of Bulgarian jackals. The analysed adult samples were as follows: 20from POP_1 (11 males and 9 females); 15from POP_2 (8 males and 7 females);19 from POP_3(10 males and 9 females). 
The craniological description of the golden jackals from Bulgaria was based on 18 skull measurements taken with an accuracy of $0.01 \mathrm{~mm}$ according to a compiled set of craniometrical parameters, which was developed especially for the present study (Fig. 2).It included the biggest part of the metric parameters used by the scientists so far for craniological description of the golden jackal in the species' world area.
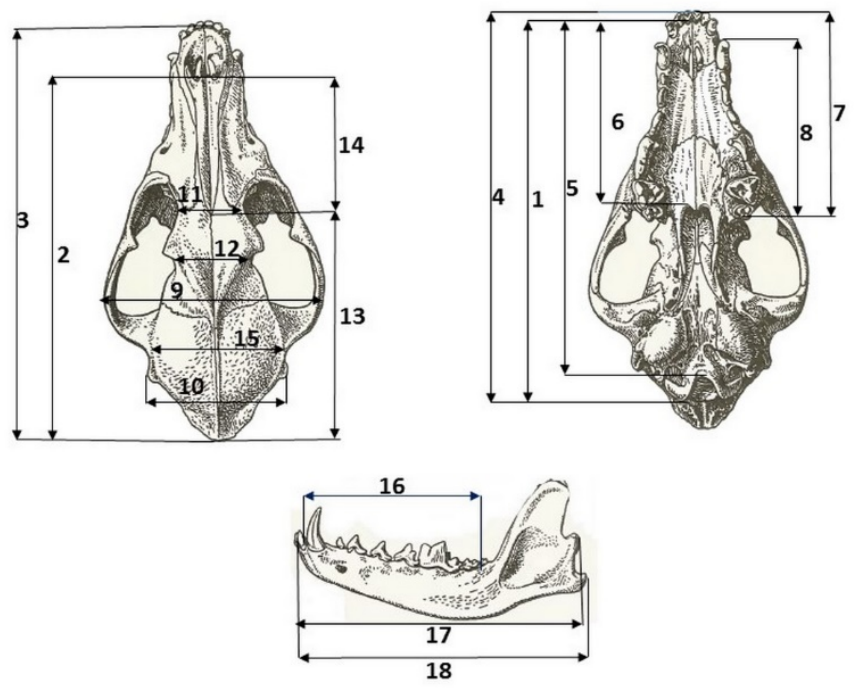

Figure 2. Scheme of the cranial characters taken on golden jackal (Canis aureus) skull: M1 - Ventral total length; M2 - Length of the skull from osnasale to prostion; M3 - Dorsal total length; M4 - Condylobasal length; M5 - Basal length; M6 - Length from the premaxilla (behind $\mathrm{I}^{1}$ ) to the palatine; M7 - Length of the upper tooth row from $\mathrm{I}^{1}$ to $\mathrm{M}^{3}$; M8 -Length of the upper tooth row from C to M3; M9 - Zygomatic breadth; M10 - Mastoid breadth; M11 - Interorbital breadth; M12 Postorbital breadth; M13 - Cranial length; M14 - Nasal length; M15 - Cranial width; M16 - Length of the lower tooth row from C to $\mathrm{M}_{2}$; M17 - Total mandible length from the alveolus I to processuscondyloideus; M18 - Mandibular length

To assess the population craniometric degree of similarity and differentiation of the populations of the golden jackal form Bulgaria with other craniometrically determined adult specimens of $C$. aureus from the European range of the species, the original craniometrical data published by Kryštufekand Tvrtkovic (1990) were used. According to the available information about the age and the gender of the specimens from Western Balkans (Dalmatia, Croatia), which they have described craniometrically, it was possible to identify only 3 adult males. These three specimens have been characterized by 8 craniometric characters (corresponding to M3, M4, M8, M9, M11, M12, M14 and M17 of our set of 18 characters) and were included in the present comparative analysis.

The initial craniometric parameters of the Bulgarian golden jackals were tested for normality using Kolmogorov-Smirnov D-statistics, and for homogeneity of variances using Levene's test. The basic statistics - the mean (X) and the standard deviation (SD) - were calculated for all studied morphometric characteristics of each investigated group of animals.

T-test for Independent Samples and one-way ANOVA followed by Bonferroni correction were used to compare and to assess the statistical significance $(p=0.05)$ of the differences in the mean values of the craniometrical parameters of the investigated golden jackals. These analyses 
were performed separately for each age and sex group and for each population. Factor analysis (Extraction method - Principal components; Factor rotation - Varimax raw) was used in the data reduction to identify a small number of factors that explain most of the variance observed in a much larger number of craniometrics parameters.

The phenetic similarity among the studied adult specimens was expressed graphically through Cluster Analysis (Joining Tree Clustering; Amalgamation (linkage) rule: Unweighted pairgroup centroid and Distance measure: Euclidean distances).

Discriminant Analysis(Forward Stepwise Analysis) was used for detecting the variables that allow discriminating the investigated specimens of golden jackal in Bulgaria according to their preliminary well-known groups in the country.

For those cranial parameters that differed significantly between the sexes (separately for sub adults and adults) two indices were calculated using their means: „Indices of sexual size dimorphism“ (ISSD) = mean size of the larger sex (males)/mean size of the smaller sex (females) and „Mean sexual dimorphism indices“ calculated as the grand mean of all intraspecific ratios of male over female values (for details see Van ValkenburghandWayne1994).All calculations were performed using the statistical package STATISTICA 2008 version 8.0 (StatSoft Inc. 2008).

\section{Results and Discussion}

The calculated basic statistical parameters (mean X and standard deviation SD) for all investigated cranial characters in both genders of each investigated group of golden jackals in Bulgaria are presented in Table 1.

Table 1. The number of specimens (N), mean length (X in [mm]) and standard deviation (SD) of each craniometric parameter in both sexes of the combined group of golden jackals(Canis aureus)

\begin{tabular}{|c|c|c|c|c|c|c|c|c|c|c|c|c|}
\hline \multirow{3}{*}{ 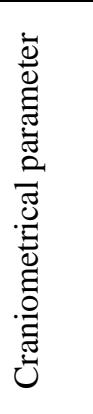 } & \multicolumn{6}{|c|}{$\begin{array}{l}\text { Common golden jackal group from the whole } \\
\text { territory of Bulgaria, } \\
\qquad \mathrm{N}=106\end{array}$} & \multicolumn{6}{|c|}{$\begin{array}{l}\text { Adult golden jackal group from different } \\
\text { populations in Bulgaria, } \\
\qquad \mathrm{N}=54\end{array}$} \\
\hline & \multicolumn{2}{|c|}{$\begin{array}{c}\text { Juveniles } \\
\mathrm{N}=12\end{array}$} & \multicolumn{2}{|c|}{$\begin{array}{l}\text { Sub adults } \\
\mathrm{N}=40\end{array}$} & \multicolumn{2}{|c|}{$\begin{array}{l}\text { Adults } \\
\mathrm{N}=54\end{array}$} & \multicolumn{3}{|c|}{$\begin{array}{l}\text { Males } \\
\mathrm{N}=29\end{array}$} & \multicolumn{3}{|c|}{$\begin{array}{l}\text { Females } \\
\mathrm{N}=25\end{array}$} \\
\hline & $\begin{array}{l}\text { Male } \\
\mathrm{N}=6\end{array}$ & $\begin{array}{c}\text { Fema } \\
\text { le } \\
\mathrm{N}=6\end{array}$ & $\begin{array}{l}\text { Male } \\
\mathrm{N}=17\end{array}$ & $\begin{array}{c}\text { Fema } \\
\text { le } \\
\mathrm{N}=23\end{array}$ & $\begin{array}{c}\text { Male } \\
\mathrm{N}= \\
29\end{array}$ & $\begin{array}{c}\text { Fema } \\
\text { le } \\
\mathrm{N}= \\
25\end{array}$ & $\begin{array}{l}\text { POP_1 } \\
\mathrm{N}=11\end{array}$ & $\begin{array}{c}\text { POP_2 } \\
\mathrm{N}=8\end{array}$ & $\begin{array}{r}\text { POP_3 } \\
\mathrm{N}=10\end{array}$ & $\begin{array}{c}\text { POP_1 } \\
\mathrm{N}=9\end{array}$ & $\begin{array}{c}\text { POP_2 } \\
\mathrm{N}=7\end{array}$ & $\begin{array}{c}\text { POP_3 } \\
N=9\end{array}$ \\
\hline M1 & 139.7 & 142.5 & 150.7 & 148.7 & 160.7 & 155.2 & 158.9 & 160.6 & 162.6 & 155.0 & 155.5 & 155.3 \\
\hline $\mathrm{SD}_{\mathrm{M} 1}$ & 2.6 & 2.4 & 2.8 & 2.3 & 5.2 & 5.3 & 2.9 & 4.2 & 7.2 & 5.0 & 5.6 & 5.9 \\
\hline M 2 & 135.0 & 133.8 & 139.8 & 137.3 & 153.1 & 145.3 & 151.0 & 153.4 & 155.2 & 145.6 & 141.9 & 147.5 \\
\hline $\mathrm{SD}_{\mathrm{M} 2}$ & 7.4 & 2.3 & 2.3 & 4.1 & 7.2 & 6.1 & 5.3 & 5.9 & 9.6 & 5.0 & 3.8 & 7.6 \\
\hline M 3 & 164.4 & 160.1 & 169.4 & 167.1 & 180.9 & 174.9 & 177.8 & 181.3 & 183.9 & 174.3 & 173.3 & 176.9 \\
\hline $\mathrm{SD}_{\mathrm{M} 3}$ & 7.4 & 5.9 & 3.4 & 2.4 & 6.8 & 5.0 & 3.7 & 4.0 & 9.8 & 2.7 & 3.8 & 7.1 \\
\hline M 4 & 146.4 & 145.4 & 153.5 & 150.6 & 163.1 & 157.9 & 161.8 & 161.2 & 166.2 & 156.8 & 157.4 & 159.5 \\
\hline $\mathrm{SD}_{\mathrm{M} 4}$ & 6.7 & 4.5 & 2.1 & 2.1 & 5.7 & 6.7 & 4.0 & 4.2 & 7.3 & 7.4 & 5.8 & 7.2 \\
\hline
\end{tabular}




\begin{tabular}{|c|c|c|c|c|c|c|c|c|c|c|c|c|}
\hline M 5 & 139.1 & 137.5 & 144.6 & 142.3 & 153.8 & 147.5 & 152.2 & 152.2 & 156.8 & 145.6 & 147.1 & 149.7 \\
\hline $\mathrm{SD}_{\mathrm{M} 5}$ & 6.8 & 3.8 & 2.3 & 2.4 & 5.7 & 5.0 & 3.8 & 4.3 & 7.5 & 4.2 & 2.6 & 6.4 \\
\hline M 6 & 69.9 & 68.7 & 72.0 & 71.2 & 77.1 & 74.2 & 75.9 & 76.0 & 79.2 & 72.4 & 74.2 & 76.0 \\
\hline $\mathrm{SD}_{\mathrm{M}}$ & 2.3 & 1.9 & 1.2 & 1.7 & 3.7 & 3.6 & 1.4 & 1.9 & 5.6 & 2.1 & 1.4 & 5.1 \\
\hline M 7 & 79.8 & 77.8 & 81.4 & 80.3 & 86.1 & 82.7 & 85.4 & 85.3 & 87.5 & 82.6 & 82.7 & 82.9 \\
\hline$\overline{\mathrm{SD}_{\mathrm{M} 7}}$ & 2.8 & 1.6 & 1.5 & 1.2 & 2.7 & 2.7 & 1.5 & 2.0 & 3.8 & 3.1 & 1.5 & 3.1 \\
\hline M 8 & 64.8 & $\begin{array}{l}63.8 \\
\end{array}$ & $\begin{array}{ll}66.8 \\
\end{array}$ & $\begin{array}{l}65.8 \\
\end{array}$ & 70.7 & 68.6 & 70.2 & 70.1 & 71.9 & 68.2 & $\begin{array}{l}67.6 \\
\end{array}$ & 69.6 \\
\hline $\mathrm{SD}_{\mathrm{M} 8}$ & 2.6 & 1.9 & 1.4 & 1.7 & 2.8 & 2.6 & 1.4 & 1.9 & 4.1 & 2.6 & 1.1 & 3.2 \\
\hline M9 & 79.5 & 79.3 & 84.6 & 83.9 & 89.6 & 87.8 & 88.1 & 90.1 & 90.9 & 87.2 & 87.0 & 89.1 \\
\hline $\mathrm{SD}_{\mathrm{M9}}$ & 6.0 & 4.0 & 3.9 & 3.4 & 4.4 & 4.2 & 3.5 & 3.3 & 5.7 & 2.7 & 3.9 & 5.6 \\
\hline M10 & 54.1 & 53.3 & 55.5 & 54.0 & 56.9 & 55.8 & 56.5 & 57.3 & 56.9 & 55.2 & 55.7 & 56.4 \\
\hline $\mathrm{SD}_{\mathrm{M} 10}$ & 1.9 & 1.7 & 1.8 & 1.2 & 1.6 & 1.9 & 1.8 & 1.8 & 1.2 & 1.1 & 1.8 & 2.5 \\
\hline M 11 & 23.1 & 23.4 & 24.5 & 25.2 & 27.2 & 26.1 & 26.0 & 27.1 & 28.5 & 25.7 & 25.0 & 27.3 \\
\hline $\mathrm{SD}_{\mathrm{M} 11}$ & 1.3 & 3.0 & 1.7 & 1.7 & 2.7 & 2.4 & 1.6 & 1.7 & 3.8 & 2.2 & 1.7 & 2.7 \\
\hline M 12 & 31.3 & 28.9 & 30.2 & 30.2 & 31.1 & 29.8 & 30.2 & 30.3 & 32.8 & 29.6 & 28.5 & 31.1 \\
\hline $\mathrm{SD}_{\mathrm{M} 12}$ & 2.4 & 1.6 & 2.1 & 2.4 & 2.9 & 3.3 & 2.4 & 2.1 & 3.5 & 3.3 & 1.6 & 3.9 \\
\hline M 13 & $\begin{array}{l}87.8 \\
\end{array}$ & 84.9 & 87.9 & 86.2 & 97.7 & 92.6 & 95.4 & 98.1 & 99.9 & 91.7 & $\begin{array}{l}89.3 \\
\end{array}$ & 95.9 \\
\hline $\mathrm{SD}_{\mathrm{M} 13}$ & 5.1 & 5.3 & 2.68 & 4.5 & 5.8 & 5.7 & 4.3 & 4.0 & 7.7 & 4.8 & 2.3 & 6.9 \\
\hline M 14 & 47.1 & 49.5 & 51.9 & 51.1 & 55.4 & 52.7 & 55.6 & 55.3 & 55.3 & 54.0 & 52.6 & 51.5 \\
\hline $\mathrm{SD}_{\mathrm{M} 14}$ & 2.1 & 1.6 & 3.1 & 2.5 & 2.8 & 2.6 & 2.8 & 3.4 & 2.6 & 2.9 & 2.7 & 1.9 \\
\hline M 15 & 79.4 & 79.3 & 84.6 & 83.9 & 89.6 & 87.7 & 88.1 & 90.1 & 90.9 & $\begin{array}{l}86.8 \\
\end{array}$ & 87.0 & 89.1 \\
\hline $\mathrm{SD}_{\mathrm{M} 15}$ & 5.7 & 4.0 & 3.9 & 3.4 & 4.4 & 4.3 & 3.5 & 3.3 & 5.7 & 2.9 & 3.9 & 5.6 \\
\hline M 16 & 70.0 & 68.8 & 72.5 & 71.2 & 76.5 & 73.6 & 75.8 & 75.5 & 78.0 & 72.5 & 73.1 & 75.0 \\
\hline $\mathrm{SD}_{\mathrm{M} 16}$ & 2.8 & 1.5 & 2.0 & 2.0 & 2.8 & 2.8 & 1.6 & 1.5 & 4.0 & 2.3 & 1.5 & 3.5 \\
\hline M 17 & 112.8 & 112.0 & 117.2 & 115.6 & 125.0 & 119.7 & 123.3 & 125.0 & 126.9 & 117.9 & 119.4 & 121.7 \\
\hline $\mathrm{SD}_{\mathrm{M} 17}$ & 5.4 & 4.5 & 1.9 & 2.3 & 4.9 & 4.5 & 2.3 & 3.4 & 7.2 & 4.0 & 3.5 & 5.2 \\
\hline M 18 & 112.3 & 111.5 & 117.8 & 116.6 & 126.0 & 120.5 & 124.5 & 126.7 & 127.1 & 119.7 & 120.6 & 121.1 \\
\hline
\end{tabular}




\begin{tabular}{|l|l|l|l|l|l|l|l|l|l|l|l|l|}
\hline $\mathrm{SD}_{\mathrm{M} 18}$ & 6.3 & 5.1 & 2.6 & 2.5 & 4.7 & 3.9 & 2.7 & 3.2 & 6.9 & 3.6 & 3.3 & 4.9 \\
\hline
\end{tabular}

The number of specimens (N), mean length (X in [mm]) and standard deviation (SD) of each craniometric parameter in both sexes of the combined group of golden jackals(Canis aureus) from the whole territory of the country and in the samples from the investigated localities in Bulgaria: POP_1 inhabiting Sakar-Strandzha region; POP_2 inhabiting the Upper Thracian Plain and POP_3 inhabiting the western part of the Sub-Balkan valleys. Symbols of the characters are the same as in Fig. 2

Due to the relatively small sample size the juvenile specimens were excluded from the subsequent comparative analyses.

The results of the test for significant differences between the means of the 18studied cranial parameters between both genders in the remaining two age groups of the golden jackals "subadult" and "adult”,each including specimens from the whole territory of the country, were as follows:

a) In the age group of the "subadult" specimens sexual craniometric differences were found between the mean values of8 (44.4\%) studied characters - Ventral total length (M1), Length of the skull from osnasale to prostion (M2), Dorsal total length (M3), Condylobasal length (M4), Basal length (M5), Length of the upper tooth row from $\mathrm{I}^{1}$ to $\mathrm{M}^{3}$ (M7), Mastoid breadth (M10) and Total mandible length from the alveolus I to processus condyloideus (M17).

b) In the age group of the "adult" specimens a significant sexual dimorphism was found between the mean values of 14 characters (77.7\%) - Ventral total length (M1), Length of the skull from osnasale to prostion (M2), Dorsal total length (M3), Condylobasal length (M4), Basal length (M5), Length of the upper tooth row from I1 to M3, Length from premaxilla (behind $\mathrm{I1}$ ) to the palatine (M6), Length of the upper tooth row from $\mathrm{I}^{1}$ to $\mathrm{M}^{3}$ (M7),Length of the upper tooth row from $\mathrm{C}$ to $\mathrm{M}^{3}$ (M8), Mastoid breadth (M10), Cranial length (M13), Nasal length (M14), Length of the lower tooth row from $C$ to $M_{2}$ (M16),Total mandible length from the alveolus I to processus condyloideus (M17) and Mandibular length (M18).

The comparison between the craniometric characters with an expressed sexual dimorphism in both age groups showed that 8 of them (M1, M2, M3, M4, M5, M7, M10 and M17) displayed sexual differences even in the age group of the subadults. In the next age group (adult) seven more craniometric characters (M6, M8, M10, M13, M14, M16 and M18) begin to exhibit sexual dimorphism. Thus, in the "adult"agegrouponly4 of all the studied characters (M9, M11, M12 and M15 or 22.2\%) did not express any sexual dimorphism in their mean values and these characters were related to the skull's width.

The "Mean sexual dimorphism indices” and“ Indices of sexual size dimorphism” calculated for the cranial parameters, the mean values of which differed significantly (after Bonferroni correction) between the sexes (separately for "sub adult" and "adult" groups from the whole country and between adult specimens in different populations) were presented in Table 2.

Table 2. Values of „Mean sexual dimorphism indices” and “Indices of sexual size dimorphism” for the cranial parameters 


\begin{tabular}{|c|c|c|c|c|c|}
\hline & \multicolumn{2}{|c|}{ Age groups } & \multicolumn{3}{|c|}{ Population } \\
\hline & Subadult & Adult & POP_1 & POP_2 & POP_3 \\
\hline \multicolumn{6}{|c|}{ Mean sexual dimorphism indices } \\
\hline $\mathbf{X}$ & 1.01702 & 1.03924 & 1.03722 & 1.04352 & 1.04534 \\
\hline SD & 0.00489 & 0.00898 & 0.00925 & 0.01815 & 0.02009 \\
\hline Parameter & \multicolumn{5}{|c|}{ Indices of sexual size dimorphism } \\
\hline M 1 & 1.01345 & 1.03543 & 1.02516 & - & 1.04701 \\
\hline M 2 & 1.01820 & 1.05368 & 1.03709 & 1.08104 & 1.05220 \\
\hline M 3 & 1.01376 & 1.03431 & 1.02008 & 1.04616 & _- \\
\hline M 4 & 1.01926 & 1.03293 & 1.03881 & 1.02410 & 1.0042 \\
\hline M 5 & 1.01616 & 1.04271 & 1.04533 & 1.03467 & 1.04743 \\
\hline M 6 & _ & 1.03908 & 1.04834 & 1.02426 & - \\
\hline M 7 & 1.01370 & 1.04111 & 1.03390 & 1.03144 & 1.05549 \\
\hline M 8 & _ & 1.03061 & 1.02933 & 1.03698 & 1.03305 \\
\hline M 9 & _- & _- & - & _- & - \\
\hline M 10 & 1.02778 & 1.01971 & & & \\
\hline M 11 & - & _- & _- & _- & _- \\
\hline M 12 & _- & _- & _- & _- & _- \\
\hline M 13 & & 1.01972 & & 1.06979 & - \\
\hline M 14 & _ & 1.05123 & _- & _- & 1.07379 \\
\hline M 15 & - & - & - & - & - \\
\hline M 16 & - & 1.03940 & 1.04552 & 1.03283 & - \\
\hline M 17 & 1.01384 & 1.04428 & 1.04580 & 1.04690 & - \\
\hline M 18 & - & 1.04564 & 1.04010 & 1.05058 & 1.04955 \\
\hline
\end{tabular}

Values of „Mean sexual dimorphism indices” and “Indices of sexual size dimorphism” for the cranial parameters, the mean values of which differed significantly between the sexes of the golden jackal (Canis aureus) in Bulgaria (separately for "subadult" and "adult" groups from the whole country and between adult specimens in different populations). POP_1, inhabiting Sakar-Strandzha region; POP_2 inhabiting the Upper Thracian Plain and POP_3 inhabiting the western part of the Sub-Balkan valleys. The symbols of the characters are the same as in Fig. 2

The assessment of the "Mean sexual dimorphism indices" showed that their values were of the same magnitude in all age and population groups. The comparison of the values of the "Indices of sexual size dimorphism"between the groups of subadultand adult specimens showed that they differed significantly at $\mathrm{p}<0.05$. The differences in the average values of "Indices of sexual size dimorphism" between the three populations were not statistically significant.

The factor analysis revealed 2 factors explaining the biggest part of the variation of the studied groups of the golden jackals of both sexes separately in both age groups:

a) Group "subadult" specimens:in the first factor the highest values belonged to 8craniologicalcharacters describing the skull lengths(from M1to M8); the highest values in thesecond factor belonged to 3 characters related to the breadth dimensions of the skull (M9, M11 and M15) and one (M18)related to the mandibular length;Cumulative \% - 58.81;

b) Group "adult" specimens: in the first factor the highest values belonged to 8characters describing the skull lengths (M1 to M8) and tree (M16 to M18)related to the mandibular length; the highest values in the second factor belonged to 4 characters related tothe breadth dimensions (M9 to M11 and M15); Cumulative \% -80.24\%. 
This analysis showed that the craniological characters included in the first and the second factors explaining the biggest part of the variation of the golden jackals of both sexes were almost the same in the two studied age groups.The only difference was that in the group ofadult specimens two additional characters (M16 and M17) were included into the first factor.

The multivariate analysis of the sexual craniometric differences (Forward Stepwise Analysis)separately in both age groups - „subadult” and “adult” from the whole country was able to choose the variables to be included in models of discriminationof specimens by gender. The variables that allow discriminating the investigated specimens from each age group by sex are shown in Table 3.

Table 3 Overview of the results of the multivariate analysis (Forward Stepwise Analysis) of the sexual craniometric variety within the age groups

\begin{tabular}{|l|l|l|}
\hline Age group & \multicolumn{1}{|c|}{ Subadultspecimens } & \multicolumn{1}{|c|}{ Adultspecimens } \\
\hline Summary & Wilks' Lambda: 0.3620, approx. F (9,30) = 5.8728; p & Wilks' Lambda: 0.3745 approx. F (10,43) = 7.1807; p < \\
& $<0.0001$ & 0.0000
\end{tabular}

Table 3 shows Overview of the results of the multivariate analysis (Forward Stepwise Analysis) of the sexual craniometric variety within the age groups „subadult” and “adult” of the Bulgarian golden jackals (Canis aureus). The symbols of the characters are the same as in Fig. 2

The stepwise analysis performed on all variables has produced Classification Functions to classify the specimens by gender in the age group "subadult" based on 9 measurements (M4, M5, M6, M9, M10, M11, M14, M13, M18). The Classification Functions, which classify the specimens by gender in the age group "adult” contain 10 measurements (M5, M6, M7, M8, M11, M13, M14, M15, M16, M18).The comparative analysis of the craniometric characters included in these ClassificationFunctionsrevealed their specificity: both ClassificationFunctionscontain the craniometric characters M5, M6, M11, M13, M14 andM18; charactersM4, M9 and M10were included only in the ClassificationFunctionfor theage group "subadult”, while characters M7, M8, M15 and M16were included only in the Classification Function for the age group "adult”.TheClassification Functions derived separately for the two age groups to classify the specimens by gender gave relatively good results.

The extended population analysis of the sexual dimorphism (one-way ANOVA followed by Bonferroni correction) in skull size, carried out separately in the adult specimens from the 3 studied populations of Bulgarian jackals showed that it was strongly expressed in all of them.

The analyses of the inter-population statistical significance (one-way ANOVA followed by Bonferroni correction) in the population's craniometric features of the golden jackal in Bulgaria, separately in both genders, showed that: (i) in the male specimens, none of the 18 studied cranial parameters did reveal significant differencesin the three studied populations; (ii) in the female specimensonly M13 among all the 18 cranial parameters revealed significant differences in the investigated populations. 
The investigation of the multivariate craniometrical differentiation carried out separately in the males and in the females from the three studied populations showed that the applied Multiple Group Discriminant Analysis (Forward Stepwise Analysis) was able to "build” a model classifying both males and females to the population, from which they originated (Table 4). In both cases,thederivedmodelsofdiscrimination classify correctly the studied specimens into their previously known population.

Table 4. Overview of the results of the multivariate analysis of the craniometric variety in the adult Bulgarian golden jackals (Canis aureus)

\begin{tabular}{|c|c|c|}
\hline & Adultmale specimens & Adult female specimens \\
\hline Summary & $\begin{array}{l}\text { Wilks' Lambda: 0. } 0774 \text { approx. F }(20,34)=4.6034 ; \\
\text { p }<0.0000\end{array}$ & $\begin{array}{l}\text { Wilks' Lambda: } 0.0666 \text { approx. F }(20,26)=3.8933 ; \mathrm{p}< \\
0.0007\end{array}$ \\
\hline $\begin{array}{l}\text { Classification } \\
\text { Functions }\end{array}$ & $\begin{array}{l}\mathrm{Y}_{\text {POP_1 }}=-2.33 \mathrm{M} 12+2.87 \mathrm{M} 3-78.50 \mathrm{M} 16+31.45 \\
\mathrm{M} 18-23.37 \mathrm{M} 2-34.27 \mathrm{M} 8-20.48 \mathrm{M} 5+103.51 \mathrm{M} 7 \\
+27.65 \mathrm{M} 1-34.84 \mathrm{M} 6-1906.02 \\
\mathrm{Y}_{\mathrm{POP} \_2}=-3.94 \mathrm{M} 12+26.50 \mathrm{M} 3-91.14 \mathrm{M} 16+37.40 \\
\mathrm{M} 18-24.96 \mathrm{M} 2-32.95 \mathrm{M} 8-22.75 \mathrm{M} 5+109.24 \mathrm{M} 7 \\
+29.03 \mathrm{M} 1-36.46 \mathrm{M} 6-2074.55 \\
\mathrm{Y}_{\text {POP_3 }}=-1.05 \mathrm{M} 12+23.86 \mathrm{M} 3-73.34 \mathrm{M} 16+28.25 \\
\mathrm{M} 18-21.90 \mathrm{M} 2-36.16 \mathrm{M} 8-19.74 \mathrm{M} 5+102.18 \mathrm{M} 7 \\
+27.59 \mathrm{M} 1-34.36 \mathrm{M} 6-1918.25\end{array}$ & 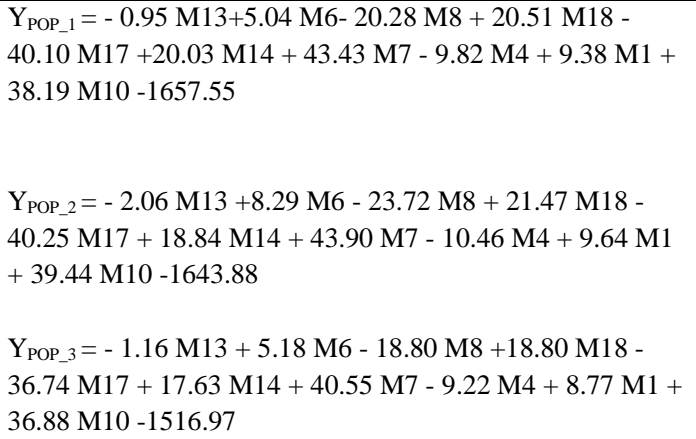 \\
\hline $\begin{array}{c}\text { Correct } \\
\text { classification [\%] }\end{array}$ & $\begin{array}{l}\text { Total: 93.13; POP_1: 90.91; POP_2: 100.00; POP_3: } \\
90.00\end{array}$ & Total: 96.00; POP_1: 88.89; POP_2: 100.00; POP_3:1000.00 \\
\hline
\end{tabular}

Table 4.shows Overview of the results of the multivariate analysis of the craniometric variety in the adult Bulgarian golden jackals (Canis aureus) from three different geographic regions: POP_1 inhabiting Sakar-Strandzha region; POP_2 inhabiting the Upper Thracian Plain and POP_3 inhabiting the western part of the Sub-Balkan valleys. The symbols of the characters are the same as in Fig. 2

The comparative analysis of the set of craniometric characters, included in each Classification Function to work out a population specific equation classifying the adult male and female golden jackals to one of the three studied populations in Bulgaria, manifested their distinctness. Only 5 craniometric characters (M1, M6, M7, M8, M18) of the 15 included in these Classification Functions (M1, M2, M6, M3, M4, M5, M7, M8, M10, M12, M13, M14, M16, M17 and M18),were common; 5 characters (M2, M3, M5, M12, M16) entered only into the Classification Function for the adult males and another 5 characters (M4, M13, M10, M14, M17) were included only in the Classification Function for the adult females.

The degree of phenotypic craniological similarity was assessed separately between males and between females from the three Bulgarian populations of the golden jackal by the multivariate estimation of their skull features and was manifested by the results of the cluster analysis (Fig.3). 


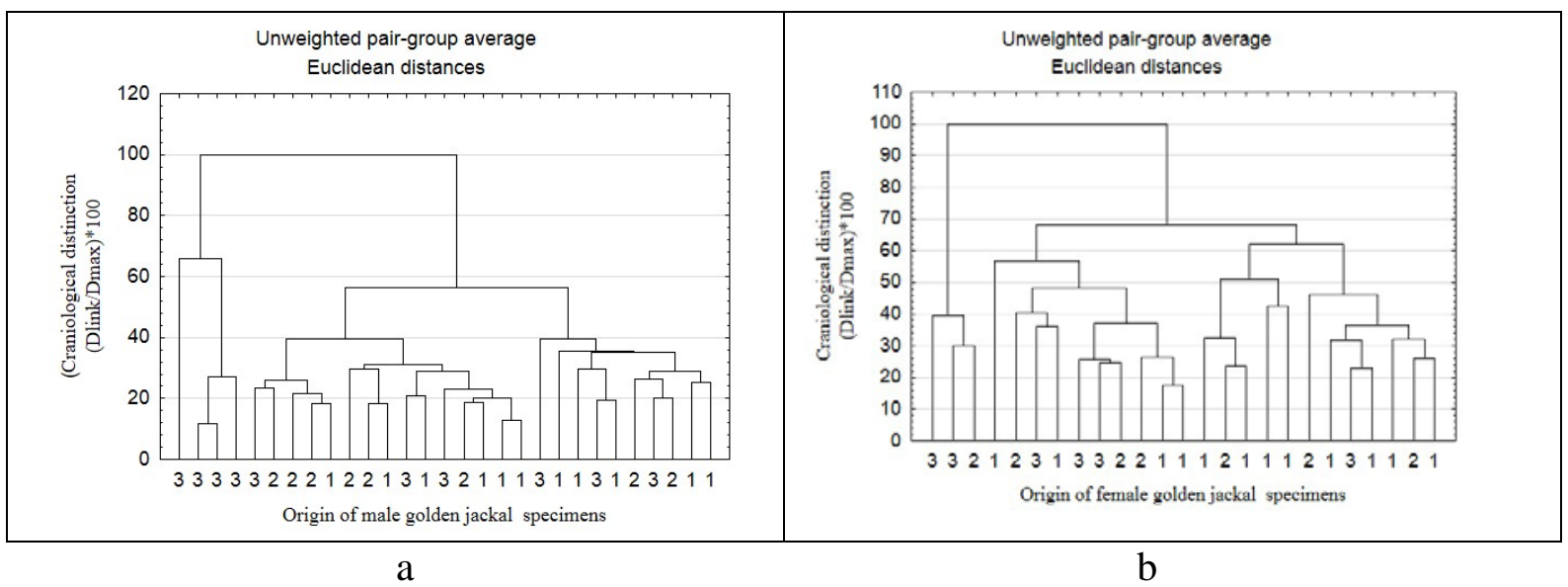

Figure 3.Phenotypic craniological distinction of the male (a) and the female (b) specimens of the golden jackal (Canis aureus) from the investigated localities in Bulgaria: 1 - Sakar-Strandzha region; 2 - Upper Thracian Plain and 3 - western part of the Sub-Balkan valleys

They showed thatthe general pattern of craniometrical likeness of the golden jackals in Bulgaria, derived from their skull features by the joining or tree clustering algorithm, was not strongly bound to their geographic origin neither in males (Fig. 3a), nor in females (Fig. 3b)from the three studied populations. Except 4 male specimens from POP_3, detached in separate clusters, each one of the other clusters joined together specimens from different populations.

The studied male adult golden jackals form Bulgaria were compared with the craniometrically determined by Kryštufek andTvrtkovic (1990) male adult specimens of golden jackals from Dalmatia (Table 5).

Table 5. Confidence intervals craniometric characteristics of adult male golden jackals (Canis aureus)

\begin{tabular}{|c|c|c|c|c|c|c|c|c|c|c|}
\hline C.I. & Area & M3 & M4 & M8 & M9 & M11 & M12 & M14 & M17 & Source \\
\hline$-95 \%+95 \%$ & Bulgaria & 178.2 & 160.1 & 69.6 & 87.9 & 26.1 & 29.61 & 54.3 & 123.1 & Present study \\
& & 180.8 & 164.4 & 71.8 & 91.2 & 28.2 & 32.2 & 56.4 & 126.8 & $\begin{array}{c}59.6 \\
112.1\end{array}$ \\
\hline X & Dalmatia & 167.0 & 158.2 & 67.5 & 92.5 & 26.6 & 30.0 & Kryštufek andTvrtkovic \\
& & & & & & & & \\
$(1990)$
\end{tabular}

Table 5. shows confidence intervals ( \pm 95 \% C.I.) of some (M3, M4, M8, M9, M11, M12, M14 and M17) craniometric characteristics [mm] of adult male golden jackals (Canis aureus) inhabiting Bulgaria and their mean values [mm] in golden jackals from Dalmatia (Croatia). The symbols of the characters are the same as in Fig. 2. The craniometric characters of the golden jackal from Dalmatia, which values lay outside the $\pm 95 \%$ C.I. of the mean values found in the cranium of Bulgarian golden jackal, are italicized.

The comparison showed that:(i) only two of eight compared parameters (M11 and M12) were of similar size; (ii) two other parameters (M9 and M14) were larger in Dalmatian golden jackals; and (iii) the other 4 parameters (M3, M4, M8 and M17) were larger in Bulgarian golden jackals. In other words, only $28.5 \%$ of the studied craniometric parameters of both compared geographic groups of the golden jackals from Balkan Peninsula demonstrated pronounced similarity.

The UPGMA dendrogram summarising the craniometric relationships among the golden jackal populations from Bulgaria and from Dalmatia is shownin Fig.4. 


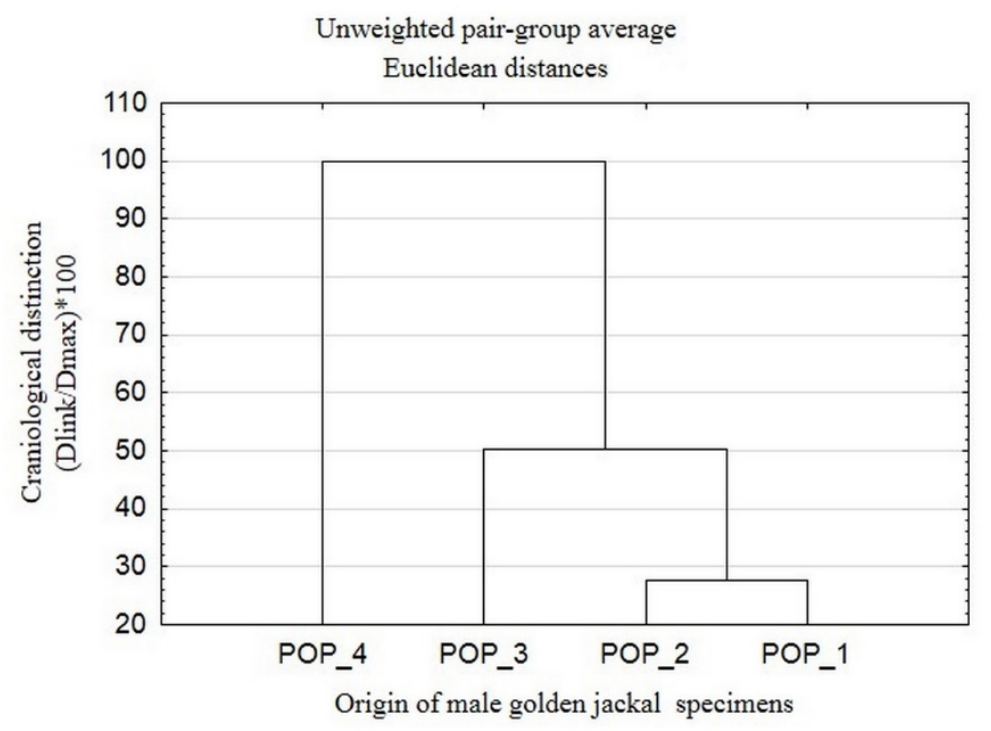

Figure 4. Phenotypic craniological distinction of the male individuals of the golden jackal(Canis aureus) from the investigated localities in Bulgaria: POP_1 - Sakar-Strandzha region; POP_2 Upper Thracian Plain and POP_3 - western part of the Sub-Balkan valleys and POP_4fromDalmatian geographic region of Croatia.

It was generated from a matrix including the same 8 metric skull characters of the specimens from the Dalmatian geographic region of Croatia and from Bulgaria, mentioned above (Dorsal total length, Condylobasal length, Length of the upper tooth row from $\mathrm{C}$ to $\mathrm{M}^{3}$, Zygomatic breadth, Inter orbital breadth, Postorbital breadth, Nasal length and Total mandible length from the alveolus I to processus condyloideus). These specimens came from populations with different density and the dendrogram showed that the degree of craniometric similarity in the Bulgarian specimens followed the degree of their population density, and all Bulgarian populations formed a common sub-cluster. The most diverged specimens were the representatives of $C$. aureus from the Dalmatian geographic region, which manifested the highest levels of morphometric differentiation (about 50\%) among all compared populations.

\section{Conclusion}

The obtained information about the phenotypic characteristics of the golden jackal in Bulgaria became a part of the necessary knowledge about the population phenotype, demonstrated by this species in different geographic populations in the country. Also, if we look at the measurements' values as indicators of cranial morphology forming phenetic variety of golden jackal (C. aureus) in Bulgaria, we can conclude that the species in the country manifests a wellexpressed sexual dimorphism, age and geographic variation of the size of the skull.

The present analysis of the sexual cranial dimorphism of the main golden jackal populations from Bulgaria showed a well expressed craniometric differentiation of both sexes. The first significant difference in the mean values of the studied craniometric parameters was found in the group of "subadult specimens". The presence of sexual craniometrical dimorphism was also confirmed in the adult specimens and was bound to certain craniometric characters of $C$. aureus in 
Europe (Kryštufek and Tvrtković; 1990;Stoyanov, 2012;Porobić etal., 2016). Therefore, the craniometric characters of the golden jackal should be analysed separately for each gender.

The results of the comparative craniological analysis suggested that the metrical features of the skull of both genders have a resolving power at population level and could be applied to classify a particular specimen as belonging to a separate geographic population of the species in Bulgaria using multidimensional craniometrical characteristics.

The craniological differences between the two sexes in the golden jackal can be attributed to a genetic predetermination of the phenotype, various diet conditions of individuals, food sources availability and habitat suitability in the three surveyed areas. However,binding them to specific factors could be a task for future genetic, ethological and physiological investigations of this species.

The patterns of population craniological relationships among the golden jackal in Bulgaria is in line with the picture depict by molecular studies of populations of golden jackals in Western Balkans on the territory of Serbia (Zachos et al., 2009), where the population genetic differentiation is too slight and the population genetic variation is very low. At the same time, the high levels of craniometric differentiation among the populations of the golden jackal inhabiting Eastern (South and South-western Bulgaria) and Western Balkans (Dalmatia, Croatia) revealed the craniological heterogeneity of the species on Balkan Peninsula.

In general, the results from the comparative population analysis of the craniometric parameters in the Bulgarian golden jackal with regard to the population craniological diversity provided a substantial biological basis for their interpretation as biomonitor characteristics in a future biological monitoring of this species in Bulgaria, i.e. helps to establish a biological basis for a species rational management, as the population approach is the leading principle of managing the wildlife.

\section{Acknowledgments}

We wish to express our gratitude to all collaborators in the field who helped in collecting the material for this study. Appreciation to the reviewers for their helpful comments. This work was supported by the Bulgarian Academy of Sciences, the Serbian Academy of Sciences and Arts bilateral project.

\section{References}

1. ABHFU 2010. Number of game animals shot in Bulgaria. Archive of the Bulgarian Hunters' and Fishermen's Union. Sofia

2. AEFA 1983. Game numbers in Bulgaria. Archive of the Executive Forest Agency of Ministry of Agriculture and Foods of R. Bulgaria. Sofia

3. AEFA 1999. Game numbers in Bulgaria. Archive of the Executive Forest Agency of Ministry of Agriculture and Foods of R. Bulgaria. Sofia

4. AEFA 2014. Game numbers in Bulgaria. Archive of the Executive Forest Agency of Ministry of Agriculture and Foods of R. Bulgaria. Sofia

5. Arnold, J.,HumerA.,Heltai, M.,Murariu, D.,Spassov, N.,Hacklander, K. (2012) Current status and distribution of golden jackals Canis aureus in Europe, Mammal Review42, pp. 1-11

6. Atanasov, N. (1953) Studies on the golden jackal (Canis aureus L. 1758) in Bulgaria, Zoology Bulletin of Bulgarian Academy of Sciences, pp. 189-207. [in Bulgarian]

7. Botev, N.,Kolev, I.,Ivanov, P. (1979) Jackal in Bulgaria, Hunting and fishing, 5, pp. 6-7. [in Bulgarian].

8. Georgiev, M. 1991. Physical Geography of Bulgaria. Sofia University Press. "St. KlimentOhridski". 406 p. [in Bulgarian].

9. Jhala, Y.,Moehlman, P. 2008. Canis aureus. In: IUCN red list of threatened species. Version 2010.4. www.iucnredlist.org

10. Koepfli, K.-P., Pollinger, J., Godinho, R., Robinson, J., Lea, A., Hendricks, S., Schweizer, R.M., Thalmann, O., Silva, P., Fan, Z., Yurchenko, A. A., Dobrynin, P., Makunin, A., Cahill, J.A., Shapiro, B., Álvares, F., Brito, J. C., Geffen, E., 
Leonard, J. A., Helgen, K. M., Johnson,W. E., O’Brien, S. J., Van Valkenburgh, B., Wayne, R. K. (2015). Genome-wide EvidenceReveals that African and Eurasian Golden Jackals Are Distinct Species. Current Biology 25 (16), pp.21582165doi:10.1016/j.cub.2015.06.060.

11. Kryštufek, B., Tvrtkovic, N. (1990) Variability and identity of the jackals (Canis aureus) of Dalmatia, Annalen des Naturhistorischen Museums in Wien, 91, pp. 7-25.

12. Lombaard, D. (1971) Age determination and growth curves in the black-backed jackal, Annals of the Transvaal Museum,27, pp. 135-169.

13. Markov, G. (2011a). Bulgaria: the country with the largest number of European jackal, In: Kryštufek, B. (Ed.). Jackals around us,Lovec, 5, pp. 248-253.

14. Markov, G. (2011b). Population number dynamic of the jackal (Canis aureus L., 1758) in Bulgaria: past, present and future. In: Materials of International Conference of zoologists "Actual problems of protection and sustainable use of the animal world diversity. Chisinau 2011,pp. $42-43$

15. Markov, G. (2012) Jackal (Canis aureus L.) in Bulgaria: What is going on?Actazoologicabulgarica,Supplement 4, pp.: 6771

16. Novikov, G. A. (1956) Carnivorous mammal fauna of the USSR. Moscow-Leningrad. Publishing House of the Academy of Sciences of the USSR. pp. 296 (in Russian)

17. Nowak, R. M. (1999) Walker's Mammals of the World. Sixth Edition. Volume I. Johns Hopkins University Press. Baltimore.

18. Pomakov, V. (1981)Some data of the golden jackal population in Bulgaria. Regional Symposium UNESCO. Proceedings. Pp. 585-591. [In Bulgarian].

19. Porobić, J.,Ćirović, D., Jojić,V. (2016)Cranial variability of the Serbian golden jackal: Geographic variation, sexual dimorphism and allometry,ZoologischerAnzeiger - A Journal of Comparative Zoology, 261, pp. 38-47

20. Raychev, E.,Dimitrov, R.,Dimova, T.,Hristov, H. (1999) How to determine the age of the golden jackal Canis aureus by cutting-teeth attrition and ossification of basal cranial synchondroses, Bulgarian Journal of Agricultural Science, 5, pp. 807-810

21. Sillero-Zubiri C.,Hoffmann, M. Macdonald, D. W. (2004) Canids: Foxes. Wolves. Jackals and Dogs. Status Survey and Conservation Action Plan. IUCN/SSC Canid Specialist Group. IUCN. Gland. Switzerland and Cambridge. UK. Available at: http://data.iucn.org/dbtw-wpd/edocs/2004-041/CANID5.pdf;

22. Spassov, N. (1989)The position of jackals in the Canis genus and life-history of the golden jackal (Canis aureus L. 1758) in Bulgaria and on the Balkans,Historianaturalisbulgarica, 1, pp. 44- 56.

23. Spassov, N. (2007)The Jackal. Canis aureus (Linnaeus 1758). - In: Miteva S., MihovaB.,Georgiev,K.,PetrovB.,VansinkD. (eds) The Mammals Important for Conservation in Bulgaria, Dutch Mammal Society VZZ. Arnhem, the Netherlands, 6, pp. 234-238.

24. StatSoft. Inc. (2008) STATISTICA (Data analysis software system). Version 8.0. www.statsoft.com.

25. Stoyanov, S. (2012)Craniometric differentiation of golden jackals (Canis aureus L. 1758) in Bulgaria. In: Proceedings. International symposium on hunting "Modem aspects of sustainable management of game population” Zemun-Belgrade. Serbia. pp. 48-56

26. Trouwborst, A., Krofel, M., Linnell, J.D.C. (2015) Legal implications of range expansions in a terrestrial carnivore: the case of the golden jackal (Canis aureus) in Europe. Biodiversity and Conservation, 24(10), pp. 2593-2610

27. Van Valkenburgh, B., Wayne, R. K. (1994) Shape divergence associated with size convergence in sympatric East African jackals, Ecology, 75 (6), pp. 1567-1581

28. Zachos, F.E.,Ćirović, D.,Kirschning, J., Otto, M.,Hartl, G. B.,Petersen, B., Honnen,A. C. (2009) Genetic variability, differentiation, and founder effect in golden jackals (Canis aureus) from Serbia as revealed by mitochondrial DNA and nuclear microsatellite loci, Biochemical Genetics, 47(3-4), pp. 241-250

Received: 28.9.2016.

Accepted: 15.12.2016.

Markov G. G., Kocheva1 M. A., Gospodinova M. G. (2017). Patterns of sexual dimorphism and phenetic variety among the populations of the golden jackal (Canis aureus) in Bulgaria: insights from craniometric data, Balkan Journal of Wildlife Research, 4(1), pp. 29-42. 